\title{
Effect of Dexamethasone on Hepatic Glucose and Insulin Metabolism after Oral Glucose in Conscious Dogs
}

Zvi Chap,* Richard H. Jones," Jesse Chou," Craig J. Hartley,‡ Mark L. Entman,‡ and James B. Field*

${ }^{*}$ Diabetes Research Center, Division of Endocrinology and Metabolism, St. Luke's Episcopal Hospital, Baylor College of Medicine; and $\ddagger$ Section of Cardiovascular Sciences, Department of Medicine, Baylor College of Medicine, Houston, Texas 77225

\begin{abstract}
To examine whether hyperinsulinemia associated with glucocorticoid treatment results solely from hypersecretion of insulin or also involves altered fractional hepatic extraction, oral glucose ( $1 \mathrm{~g} / \mathrm{kg}$ body $\mathrm{wt})$ was administered to dogs with or without dexamethasone treatment ( $2 \mathrm{mg} / \mathrm{d}$ for $2 \mathrm{~d}$ ). Dexamethasone significantly increased basal glucose and insulin concentrations in the portal vein, hepatic vein, and femoral artery, reduced basal fractional hepatic extraction of insulin from $43 \pm 4 \%$ to $22 \pm 4 \%$, and, after oral glucose, increased retention by the liver of net glucose released into the portal system from $27 \pm 4 \%$ to $53 \pm 13 \%$. Intraportal insulin infusion (1 and $2 \mathrm{mU} / \mathrm{kg}$ per $\mathrm{min}$ ) after $7 \mathrm{~d}$ of dexamethasone treatment $(2 \mathrm{mg} / \mathrm{d})$ caused less suppression of endogenous glucose production, and less exogenous glucose was required to maintain an euglycemic clamp than in control animals. Dexamethasone treatment is associated with: (a) decreased basal fractional hepatic insulin extraction contributing to hyperinsulinemia; and (b) less suppression of endogenous glucose production and increase in peripheral uptake in response to insulin, but no reduction in net hepatic glucose uptake after oral glucose.
\end{abstract}

\section{Introduction}

Glucocorticoids in excess cause hyperglycemia and hyperinsulinemia in the basal state and after oral glucose ingestion (1). This insulin-resistant state primarily involves post-receptor defects in peripheral tissues (impaired glucose transport) (2). However, some studies indicate that insulin resistance also exists at the hepatic level, with elevated basal glucose production after 7 d of steroid administration (3), and increased hepatic glucose output after cortisol infusion (4). The effect of steroids on hepatic uptake of glucose after its oral administration has not been examined previously. Although glucocorticoids directly inhibit insulin secretion (4-9), the hyperinsulinemia has been attributed to enhancement of stimulation of the B cell by the elevated glucose concentrations that result from insulin resistance (10). The present study examined the possibility that dexamethasone might alter the fractional hepatic extraction of insulin, thereby contributing to the hyperinsulinemia and the effect of the steroid on hepatic glucose metabolism after oral glucose administration.

\section{Methods}

\section{Animals and surgery}

Healthy adult male and female mongrel dogs weighing 18-30 kg were anesthetized with intravenous sodium pentobarbitol $(25 \mathrm{mg} / \mathrm{kg}$ body wt)

Address reprint requests to Dr. Field.

Received for publication 28 February 1986.

J. Clin. Invest.

(c) The American Society for Clinical Investigation, Inc.

0021-9738/86/11/1355/07 \$1.00

Volume 78, November 1986, 1355-1361 after an overnight fast (18 h). After a midline incision, pulsed rangegated ultrasonic Doppler flow probes were placed around the portal vein and the hepatic artery as described previously (11). Sampling microboresiliconized plastic catheters (American Scientific Products Div., American Hospital Supply Corp., McGaw Park, IL) were placed in the portal vein, hepatic vein, and the femoral artery as reported previously (12). The portal vein sampling catheter lay immediately below the portal vein bifurcation. The left common hepatic vein was catheterized through the superficial jugular vein using subdiaphragmatic control by hand. The tip of the two side-hole catheter was advanced into the hepatic vein 1.5-2.0 $\mathrm{cm}$ from the edge of the liver. In the experiments with insulin infusion and glucose turnover, a catheter was placed in the superior mesenteric vein for the infusion of insulin and another in the external jugular vein for the infusion of the glucose tracer $\left(\left[3-{ }^{3} \mathrm{H}\right]\right.$ glucose). The catheters were flushed daily with $2 \mathrm{ml}$ heparinized saline $(50 \mathrm{U} / \mathrm{ml})$ to prevent thrombotic occlusion. After at least $2 \mathrm{wk}$ of recovery from surgery, experiments were conducted after an overnight fast in conscious, unrestrained dogs. Experiments were done only on animals whose hematocrits were $>30 \%$ and who appeared in healthy condition with good appetite and normal stools. Blood samples for glucose, insulin, and glucagon were obtained simultaneously from the femoral artery, portal vein, and hepatic vein, with continuous measurement of portal and hepatic artery blood flows. In the glucose turnover experiments, blood samples were taken from the portal vein and femoral artery only.

\section{Experimental procedures}

Protocol I: control oral glucose group. After a 30-min control period, nine dogs each consumed $1.0 \pm 0.1 \mathrm{~g} / \mathrm{kg}$ body wt glucose ( $10 \%$ solution) within 1-2 min. Blood samples were obtained at $-30,-20,-10,0,10$, 20, 30, 45, 60, 75, 90, 105, 120, 150, and $180 \mathrm{~min}$.

Protocol II: oral glucose in dexamethasone-treated dogs. Nine dogs were given oral dexamethasone (decadron, Merck Sharp \& Dohme Div., Merck \& Co., Inc., West Point, PA) $2 \mathrm{mg} / \mathrm{d}$ as a single dose for $2 \mathrm{~d}$. On the third day the same experiment was carried out as in Protocol I.

Protocol III: insulin infusion with an euglycemic clamp. After a 30min control period, insulin was infused intraportally into eight dogs at $1 \mathrm{mU} / \mathrm{kg}$ per min from $0-75 \mathrm{~min}$ and at $2 \mathrm{mU} / \mathrm{kg}$ per min from 75$150 \mathrm{~min}$. Hypoglycemia was prevented by infusion of dextrose $(5 \%)$ into the external jugular vein at rates appropriate to maintain the dogs' basal glucose concentration. Adjustments of the glucose infusion rates were based upon plasma glucose determinations every $5 \mathrm{~min}$. The infusion of exogenous glucose was stopped simultaneously with the termination of the hormone infusion. For isotopic determination of glucose appearance, a priming dose $(48 \mu \mathrm{Ci})$ of $\left[3-{ }^{3} \mathrm{H}\right]$ glucose (New England Nuclear, Boston, MA, specific activity $12.3 \mathrm{Ci} / \mathrm{mmol}$ ) was administered at -150 min followed by infusion of $0.4 \mu \mathrm{Ci} / \mathrm{min}$ during a 150-min equilibration period and 180-min experimental period. The coefficient of variation of glucose-specific activity during the final 30 -min equilibration period (four samples) was $2.1 \pm 0.5 \%$ (mean \pm SEM). Blood samples from the portal vein and femoral artery were obtained at $-30,-20,-10,0,15,30,45$, $60,75,90,105,120,135,150,165$, and $180 \mathrm{~min}$.

Protocol IV: insulin infusion with euglycemic clamp in dexamethasone-treated dogs. Protocol III was repeated in the same eight dogs after they received dexamethasone $2 \mathrm{mg} / \mathrm{d}$ for $7 \mathrm{~d}$.

\section{Analysis}

Blood flow was measured with an ultrasonic range-gated pulsed Doppler flow meter designed by Hartley et al. $(13,14)$ and as described elsewhere 
(11). The blood flow measurements were corrected to plasma flow based on hematocrits obtained every $30 \mathrm{~min}$, since glucose, insulin, and glucagon were measured in plasma. Blood samples were collected in chilled tubes containing $500 \mathrm{U}$ Trasylol (Mobay Chemical Corp., New York) and $1.2 \mathrm{mg}$ EDTA/ml blood. Plasma immunoreactive insulin was assayed using dextran-coated charcoal (15). Plasma immunoreactive glucagon was assayed with Unger's $30 \mathrm{~K}$ antibody (16). Plasma glucose was measured by glucose autoanalyzer (Beckman Instruments, Inc., Fullerton, CA) using a glucose oxidase method. The specific activity of $\left[3-{ }^{3} \mathrm{H}\right]$ glucose was measured as previously reported (17) using plasma deproteinized by the Somogyi method (18).

\section{Calculations}

The flux of glucose and hormones in each vessel was determined by multiplying plasma flow by plasma concentration. Hepatic vein plasma flow was the sum of the plasma flows in the portal vein and hepatic artery. The amount of glucose and hormones presented to the liver was the sum of the contribution from the portal vein and hepatic artery (concentration $\times$ flow). The amount leaving the liver was the product of hepatic vein concentration and hepatic vein plasma flow. The fractional hepatic extraction of hormones was calculated according to the formula: (hormone presented to the liver - hormone leaving the liver)/(hormone presented to the liver) $\times 100$. Net nonhepatic splanchnic insulin balance was derived from the formula [(portal vein insulin concentration - arterial insulin concentration) $\times$ portal flow]/body wt. This value represents pancreatic insulin secretion minus insulin uptake in the nonhepatic splanchnic bed. Calculations of the mean values of this variable and of the hepatic extraction of hormones were based on the values obtained in each individual dog and not the means of the concentrations and flow rates presented in the figures.

The net amount of glucose released into the portal system was calculated according to the formula: [(portal vein glucose - arterial glucose) $\times$ portal flow]/body wt. A positive result indicates net release into the portal system, whereas a negative one indicates net extra hepatic splanchnic glucose uptake. Total net absorption was the area above the zero line over $180 \mathrm{~min}$. The net hepatic glucose balance was determined as follows: (glucose leaving the liver - glucose presented to the liver)/ body wt. A positive balance indicates hepatic glucose output, whereas a negative one connotes hepatic glucose uptake. Total net hepatic glucose uptake was the integrated area below the zero line from the time net hepatic glucose uptake occurred until the time it ceased. Net splanchnic glucose balance was calculated by the following formula: [(hepatic vein glucose - arterial glucose) $\times$ hepatic flow]/body wt. During the euglycemic clamp, total glucose appearance was obtained by the radioisotopic determination $(19,20)$. Because the total glucose appearance is the sum of the amount of glucose infused and the residual endogenous glucose production, the latter was derived by subtracting the amount infused from the total appearance (all expressed in milligrams per kilogram per minute).

\section{Statistics}

The data are presented as the mean \pm SEM. The basal value was the mean \pm SEM of the four values obtained from -30 to $0 \mathrm{~min}$. Significant changes from basal were determined by two-way analysis of variance, followed by Duncan's new multiple range test. Differences between the data sets from control and steroid-treated groups were evaluated by oneway analysis of variance. Comparison of two means was by unpaired Student's $t$ test. $P<0.05$ was considered to indicate a significant difference.

\section{Results}

Plasma flows. Basal portal vein plasma flow was $18.0 \pm 1.3 \mathrm{ml} /$ $\mathrm{kg}$ per min in the control group as compared with $15.2 \pm 1.2 \mathrm{ml} /$ $\mathrm{kg}$ per min in the steroid-treated dogs. This difference was not statistically significant. (Fig. 1). In both groups oral glucose significantly increased portal vein plasma flow, but the incremental area was significantly less in the steroid-treated dogs $(130 \pm 20$

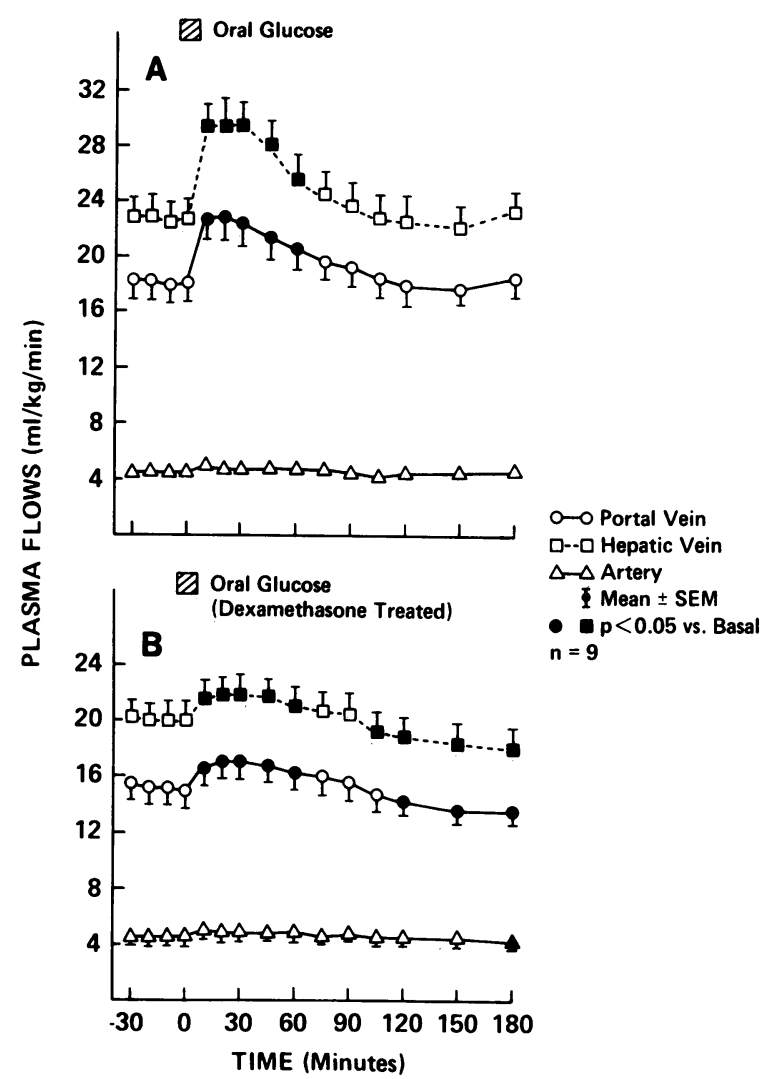

Figure 1. Plasma flows before and after oral glucose $(1 \mathrm{~g} / \mathrm{kg}$ body wt) in the portal vein (O), hepatic vein ( $\square)$, and artery $(\Delta)$, in control $(A)$ and dexamethasone-treated $(2 \mathrm{mg} / \mathrm{d}$ for $2 \mathrm{~d})(B)$ dogs.

$\mathrm{ml} / \mathrm{kg}$ per $3 \mathrm{~h}$ vs. $340 \pm 44 \mathrm{ml} / \mathrm{kg}$ per $3 \mathrm{~h}$ ). Because the hepatic artery plasma flows did not change significantly, the hepatic vein plasma flows changed in parallel with those in the portal vein.

Plasma glucose levels. In the control group, the basal hepatic vein glucose level $(89 \pm 4 \mathrm{mg} / \mathrm{dl})$ significantly exceeded those in the femoral artery $(80 \pm 3 \mathrm{mg} / \mathrm{dl})$ and portal vein $(78 \pm 3 \mathrm{mg} / \mathrm{dl})$ (Fig. 2). Steroid treatment significantly increased each of these values $(104 \pm 3,94 \pm 3$, and $93 \pm 3 \mathrm{mg} / \mathrm{dl}$ in the hepatic vein, femoral artery, and portal vein, respectively). After oral glucose was administered, glucose levels in all three vessels rose significantly above basal in both groups. Peak values were achieved at 30$45 \mathrm{~min}$ in the control group and 45-60 min in steroid-treated dogs. In the dexamethasone-treated group, glucose levels significantly exceeded those in control animals at $60,75,90$, and 105 min in arterial plasma and at 75 and $90 \mathrm{~min}$ in portal and hepatic venous samples. The incremental areas in glucose concentrations above basal did not differ significantly between control and dexamethasone-treated animals. In arterial samples the values were $5,289 \pm 1,445$ and $6,450 \pm 1,058 \mathrm{mg} \cdot \mathrm{min} / \mathrm{dl}$ per $3 \mathrm{~h}$ for the control and dexamethasone-treated groups, respectively. Corresponding portal vein values were $9,129 \pm 1,378$ and $10,204 \pm 1,008 \mathrm{mg} \cdot \mathrm{min} / \mathrm{dl}$ per $3 \mathrm{~h}$ and in the hepatic vein $6,538 \pm 1,488$ and $6,125 \pm 1,355 \mathrm{mg} \cdot \mathrm{min} / \mathrm{dl}$ per $3 \mathrm{~h}$.

Net glucose release into the portal system. Although the same size of glucose load was given in both experiments, less glucose was released into the portal system in the dexamethasone-treated dogs (Fig. 3). Of the total glucose administered, $76 \pm 4 \%$ was released into the portal system in the control animals as compared with $55 \pm 4 \%$ in the steroid-treated dogs. The peak absorption in 


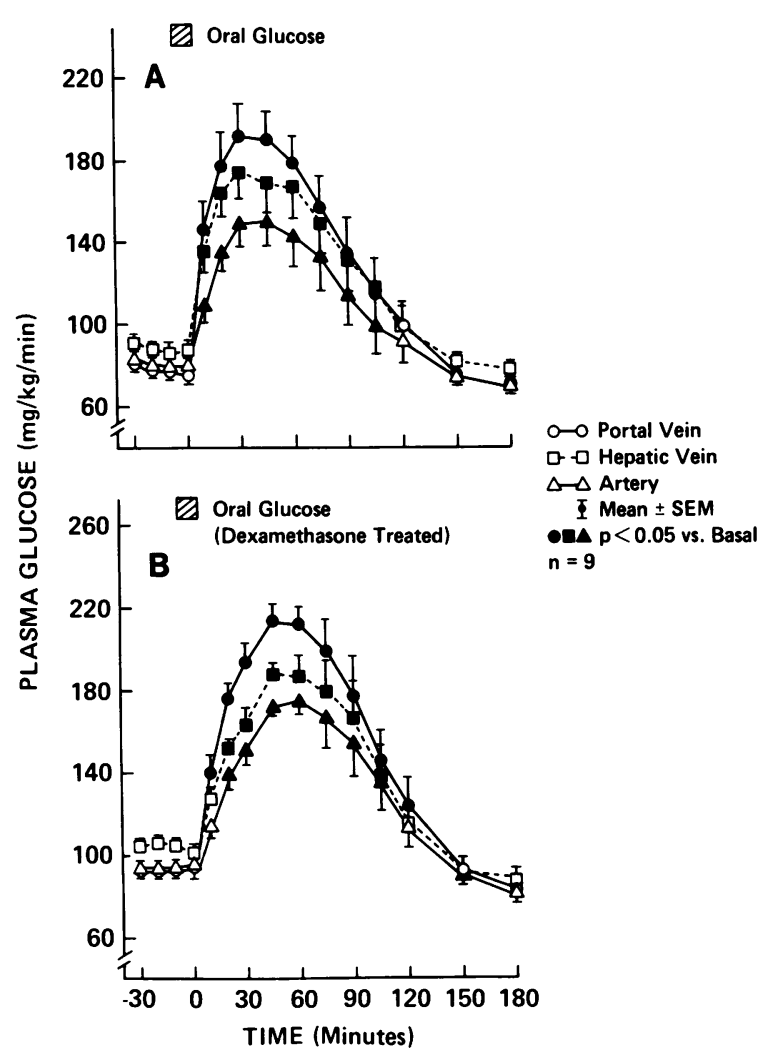

Figure 2. Plasma glucose levels before and after oral glucose in the portal vein (O), hepatic vein $(\square)$, and artery $(\Delta)$, in control $(A)$ and dexamethasone-treated $(B)$ dogs.

the controls was $9.2 \pm 1.6 \mathrm{mg} / \mathrm{kg}$ per min at $20 \mathrm{~min}$ as compared with $7.0 \pm 0.9 \mathrm{mg} / \mathrm{kg}$ per $\mathrm{min}$ at $45 \mathrm{~min}$ in the steroid-treated dogs. Despite the lower absorption of glucose in the latter group, the hyperglycemia achieved was comparable (Fig. 2).

Net hepatic and splanchnic glucose balances. The directly measured basal net hepatic glucose balance was $2.2 \pm 0.3 \mathrm{mg} / \mathrm{kg}$ per min in the basal state of the control dogs and $2.4 \pm 0.3 \mathrm{mg} /$ $\mathrm{kg}$ per min in the steroid-treated dogs (Fig. 4); these values were not significantly different. The splanchnic glucose balances were $1.9 \pm 0.2$ and $2.0 \pm 0.3 \mathrm{mg} / \mathrm{kg}$ per min in the control and dexamethasone-treated dogs, respectively and were not significantly

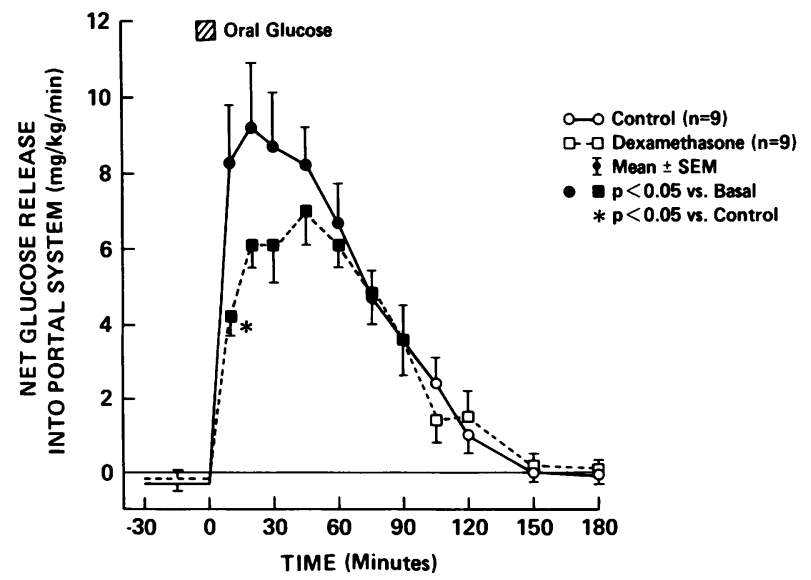

Figure 3. Net glucose release into the portal system in control (O) and dexamethasone-treated $(2 \mathrm{mg} / \mathrm{d}$ for $2 \mathrm{~d})$ ( $\square$ ) dogs.

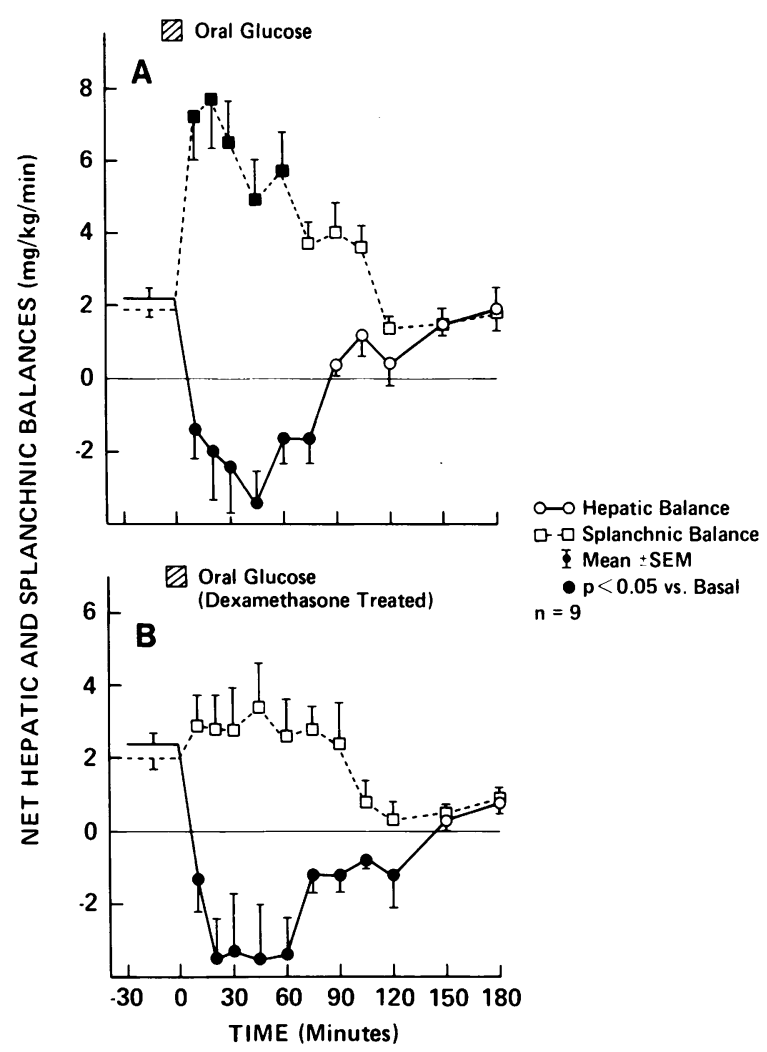

Figure 4. Net hepatic (O) and splanchnic ( $\square$ ) glucose balances in control $(A)$ and dexamethasone-treated $(B)$ dogs.

different. The difference between the hepatic and splanchnic balances indicates an uptake of $0.3-0.4 \mathrm{mg} / \mathrm{kg}$ per min glucose by the extrahepatic splanchnic tissues in the basal state. After oral glucose administration, the liver changed from net output to net uptake. Despite the reduced release of glucose into the portal system, the net hepatic uptake by the dexamethasonetreated dogs was somewhat greater than in the control dogs, although the difference did not reach statistical significance. Of the total glucose released into the portal system, $27 \pm 4 \%$ was retained by the liver in the control dogs as compared with $53 \pm 13 \%$ in the steroid-treated dogs. On an absolute basis the control dogs retained $4.5 \pm 0.9 \mathrm{~g}$ glucose in the liver as compared with $7.0 \pm 1.9 \mathrm{~g}$ in the steroid-treated dogs. Accordingly, the net splanchnic glucose output after oral glucose was significantly greater in the control dogs as compared with the steroid-treated animals (Fig. 4). While the peak value of the splanchnic glucose output was $7.7 \pm 1.4 \mathrm{mg} / \mathrm{kg}$ per min at $20 \mathrm{~min}$ in the controls, it reached only $3.4 \pm 1.2 \mathrm{mg} / \mathrm{kg}$ per $\mathrm{min}$ at $45 \mathrm{~min}$ in the steroidtreated dogs.

Insulin levels and balance. The basal insulin levels in the portal vein of the control dogs $(32 \pm 7 \mu \mathrm{U} / \mathrm{ml})$ exceeded those in the hepatic vein $(15 \pm 3 \mu \mathrm{U} / \mathrm{ml})$ and femoral artery $(11 \pm 2 \mu \mathrm{U} /$ $\mathrm{ml}$ ) and were significantly less than in the steroid-treated dogs $(63 \pm 6,44 \pm 5$, and $32 \pm 5 \mu \mathrm{U} / \mathrm{ml}$, respectively) (Fig. 5). After oral glucose administration, portal vein insulin levels rose to a maximum of $211 \pm 32 \mu \mathrm{U} / \mathrm{ml}$ at $45 \mathrm{~min}$ in the steroid-treated dogs and to $147 \pm 51 \mu \mathrm{U} / \mathrm{ml}$ at $10 \mathrm{~min}$ in the controls. Arterial insulin levels were also higher $(66 \pm 6 \mu \mathrm{U} / \mathrm{ml}$ vs. $48 \pm 10 \mu \mathrm{U} / \mathrm{ml}$ at 20 $\mathrm{min}$ ). Net nonhepatic splanchnic insulin balance (Fig. 6) was $0.37 \pm 0.11 \mathrm{mU} / \mathrm{kg}$ per min in the control groups in the basal state and reached a peak value of $2.01 \pm 0.4 \mathrm{mU} / \mathrm{kg}$ per $\min 30$ 


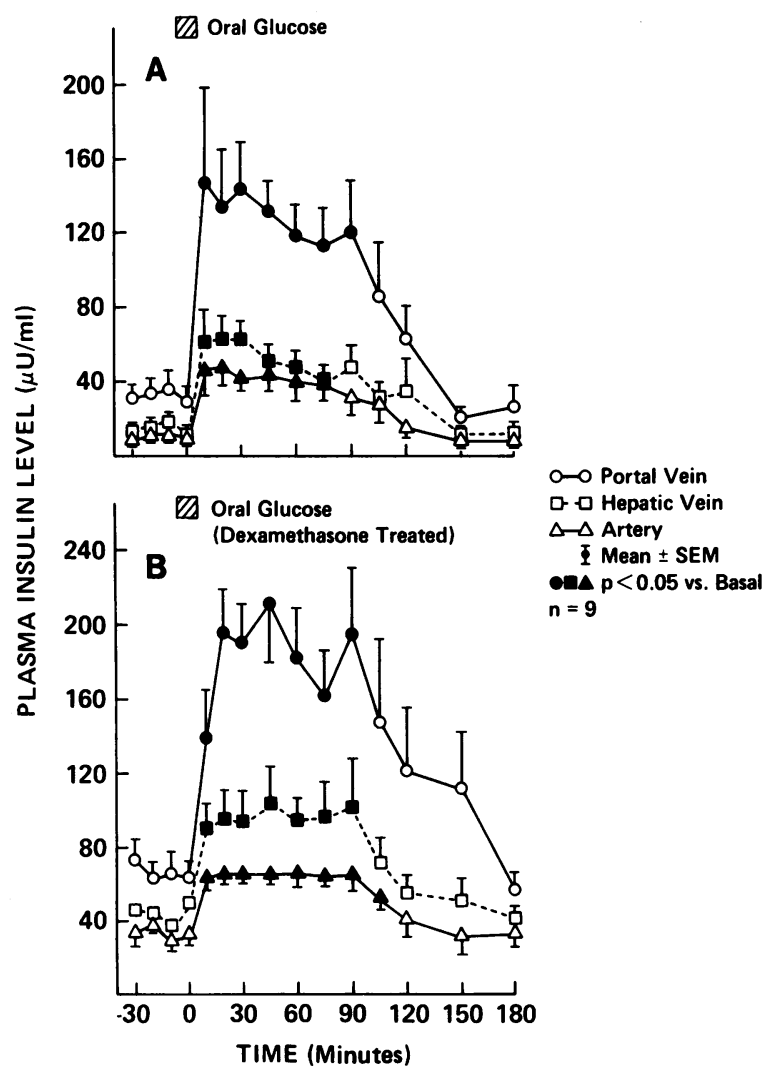

Figure 5. Plasma insulin levels before and after oral glucose in the portal vein (O), hepatic vein $(\square)$, and artery $(\Delta)$, in control $(A)$ and dexamethasone-treated $(B)$ dogs.

min after oral glucose. The basal value in dexamethasone-treated animals was $0.48 \pm 0.11 \mathrm{mU} / \mathrm{kg}$ per min, rising after oral glucose to $2.51 \pm 0.62 \mathrm{mU} / \mathrm{kg}$ per min at $45 \mathrm{~min}$. Neither in the basal state nor at any time point after oral glucose were the values significantly different between the control and experimental groups.

Increments of net nonhepatic splanchnic insulin balance above basal were $132 \pm 35 \mathrm{mU} / \mathrm{kg}$ per $3 \mathrm{~h}$ in control animals and $180 \pm 44 \mathrm{mU} / \mathrm{kg}$ per $3 \mathrm{~h}$ in dexamethasone-treated dogs. These values were not significantly different.

The basal fractional hepatic extraction of insulin was $43 \pm 4 \%$

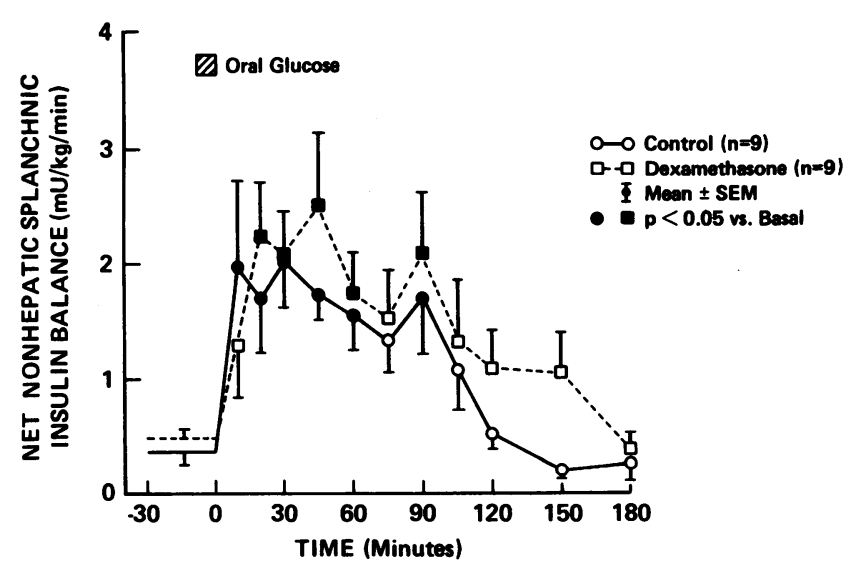

Figure 6. Net nonhepatic splanchnic insulin balance before and after oral glucose in control $(0)$ and dexamethasone-treated (ㅁ) dogs. in the control dogs, significantly greater than in the steroid-treated dogs (22 $\pm 4 \%$ ) (Fig. 7). After oral glucose administration, a similar increase in fractional hepatic extraction occurred in both groups. However, in view of their lower basal values, the increase remained significantly less in the steroid-treated dogs than in the control dogs at 10,75 , and $105 \mathrm{~min}$.

Glucagon levels and balance. Basal plasma glucagon levels were similar in the control and dexamethasone-treated dogs in all three blood vessels: $337 \pm 44$ and $395 \pm 106 \mathrm{pg} / \mathrm{ml}$ in the portal vein; $265 \pm 42$ and $257 \pm 62 \mathrm{pg} / \mathrm{ml}$ in the hepatic vein; and $215 \pm 29$ and $228 \pm 54 \mathrm{pg} / \mathrm{ml}$ in the femoral artery (Fig. 8). After oral glucose administration, glucagon levels in the portal vein decreased to a nadir of $146 \pm 34 \mathrm{pg} / \mathrm{ml}$ at $90 \mathrm{~min}$. The suppression in the steroid-treated dogs was slightly less, to a nadir of $214 \pm 47 \mathrm{pg} /$ $\mathrm{ml}$ at $105 \mathrm{~min}$. A similar trend was observed with the absolute amounts reaching and leaving the liver. The fractional hepatic extraction of glucagon was $14 \pm 6 \%$ and $22 \pm 4 \%$ during the basal state, in the control and steroid-treated dogs respectively, and did not change significantly throughout the experiments in either group (data not shown).

Steady-state insulin infusion with euglycemic clamp studies. As in the dogs treated with steroids for $2 \mathrm{~d}, 7 \mathrm{~d}$ of dexamethasone significantly increased the basal arterial glucose levels $(91 \pm 2 \mathrm{mg} /$ $\mathrm{dl}$, as compared with $76 \pm 3 \mathrm{mg} / \mathrm{dl}$ in the controls) (Fig. 9). The basal portal vein insulin levels were significantly higher in the dogs treated with dexamethasone for 7 days $(54 \pm 11 \mu \mathrm{U} / \mathrm{ml}$ as compared with $21 \pm 5 \mu \mathrm{U} / \mathrm{ml}$ before that treatment (Table I). The arterial insulin levels were $21 \pm 5$ and $8 \pm 4 \mu \mathrm{U} / \mathrm{ml}$, respectively. Basal net nonhepatic splanchnic insulin balance was $0.2 \pm 0.05 \mathrm{mU} / \mathrm{kg}$ per min in the control group. The value in the experimental group $(0.47 \pm 0.12 \mathrm{mU} / \mathrm{kg}$ per $\mathrm{min})$ was not significantly different from the controls nor from the corresponding basal balance in the dogs treated with dexamethasone for $2 \mathrm{~d}$. Isotopically estimated basal glucose appearance, $5.0 \pm 0.2 \mathrm{mg} / \mathrm{kg}$ per $\mathrm{min}$ in the steroid-treated dogs significantly exceeded that in the controls, $4.1 \pm 0.3 \mathrm{mg} / \mathrm{kg}$ per min (Fig. $8 \mathrm{~B}$ ). During the sequential infusion of insulin $(1 \mathrm{mU} / \mathrm{kg}$ per min from 0 to 75 min and $2 \mathrm{mU} / \mathrm{kg}$ per min from 75 to $150 \mathrm{~min}$ ), portal vein insulin increased to $81 \pm 3 \mu \mathrm{U} / \mathrm{ml}$ and $139 \pm 2 \mu \mathrm{U} / \mathrm{ml}$ in the steroid-treated dogs and to $68 \pm 1$ and $127 \pm 2 \mu \mathrm{U} / \mathrm{ml}$ in the control study. The arterial levels increased to $39 \pm 1$ and $65 \pm 2 \mu \mathrm{U} / \mathrm{ml}$ and to $27 \pm 1$ and $51 \pm 1 \mu \mathrm{U} / \mathrm{ml}$, respectively. The levels achieved during both infusion periods were significantly higher in the

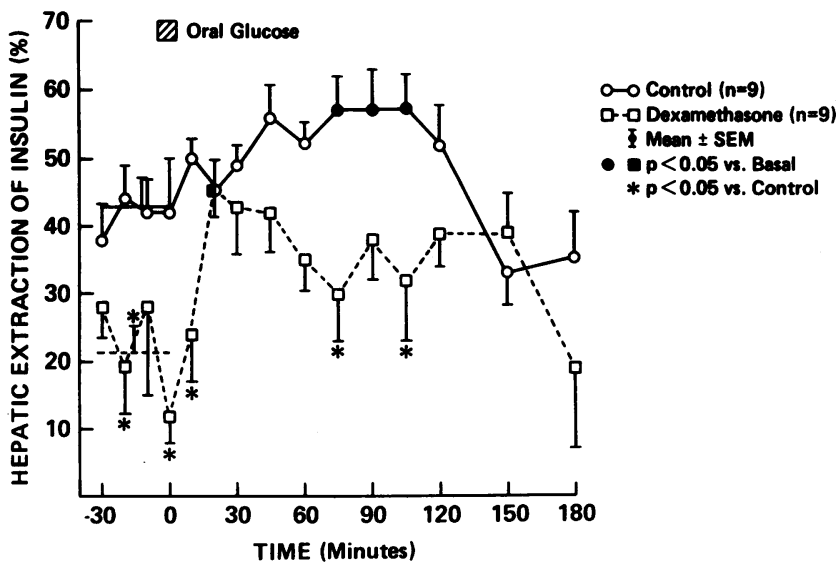

Figure 7. Fractional hepatic extraction of insulin before and after oral glucose in control $(0)$ and dexamethasone-treated $(\square)$ dogs. 


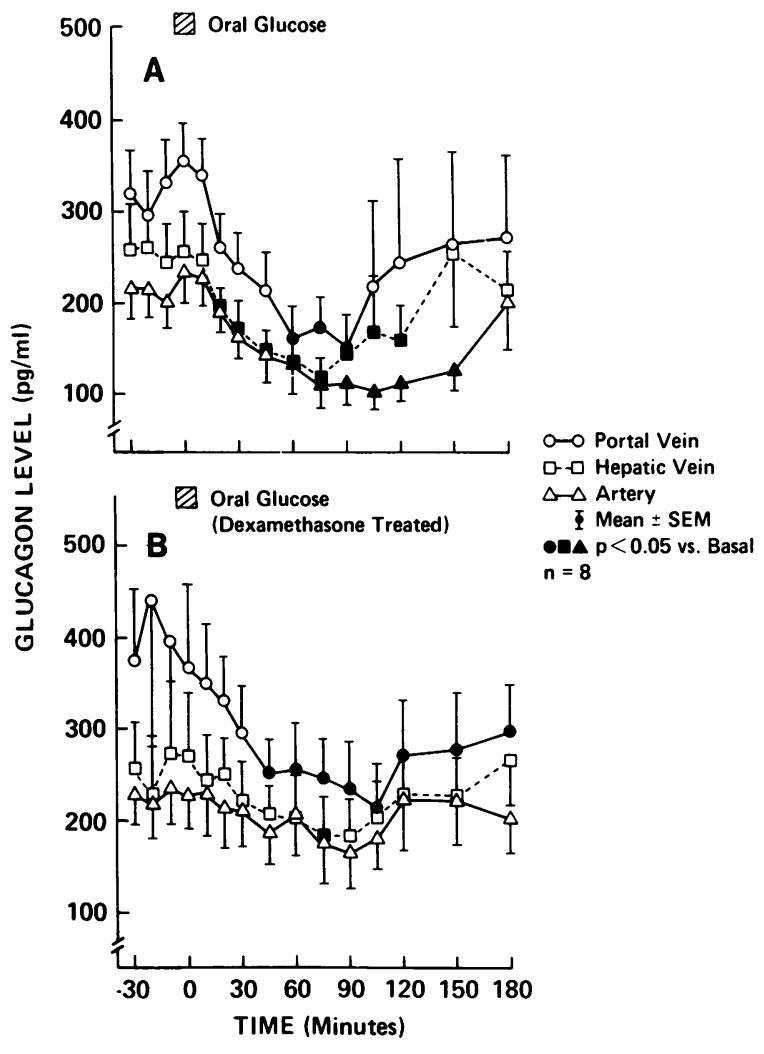

Figure 8. Plasma glucagon levels before and after oral glucose in the portal vein (O), hepatic vein $(\square)$, and artery $(\Delta)$, in control dogs $(A)$ and dexamethasone-treated $(B)$ dogs.

dexamethasone-treated dogs than in the control group. However, the increments above the respective basal values were not significantly different. Significantly less glucose was infused after dexamethasone treatment to maintain euglycemia than in the control state $(555 \pm 30$ vs. $765 \pm 75 \mathrm{mg} / \mathrm{kg}$ per $150 \mathrm{~min})$ (Fig. 9 $A)$. Endogenous glucose appearance was suppressed more in the control state, to $-0.5 \pm 0.4 \mathrm{mg} / \mathrm{kg}$ per $\mathrm{min}$ at $150 \mathrm{~min}$ as compared with $1.7 \pm 0.2 \mathrm{mg} / \mathrm{kg}$ per min after steroid treatment (Fig. $9 \mathrm{~B}$ ). The increment in glucose disposal (amount infused - decrease in endogenous glucose output) above basal values during the insulin infusion was greater in the control $(383 \pm 80 \mathrm{mg} / \mathrm{kg}$ per $150 \mathrm{~min})$ than in the dexamethasone-treated state $(191 \pm 64$ $\mathrm{mg} / \mathrm{kg}$ per $150 \mathrm{~min}$ ), despite lower arterial glucose concentration in the control animals.

\section{Discussion}

The present studies provide additional evidence for insulin resistance and diminished carbohydrate tolerance as a consequence of steroid administration (1). Thus despite higher insulin concentrations in the portal vein and the periphery, plasma glucose levels were higher in the dogs treated with dexamethasone for both 2 and $7 \mathrm{~d}$. While the incremental insulin response to oral glucose was equivalent in the control and glucocorticoid-treated dogs, the hyperglycemia persisted longer in the latter animals. Finally, during the euglycemic clamp studies less glucose had to be infused into the steroid-treated dogs to maintain their plasma glucose level even though plasma insulin concentrations achieved during the insulin infusion were somewhat higher than those in the control animals. Despite the higher insulin levels,
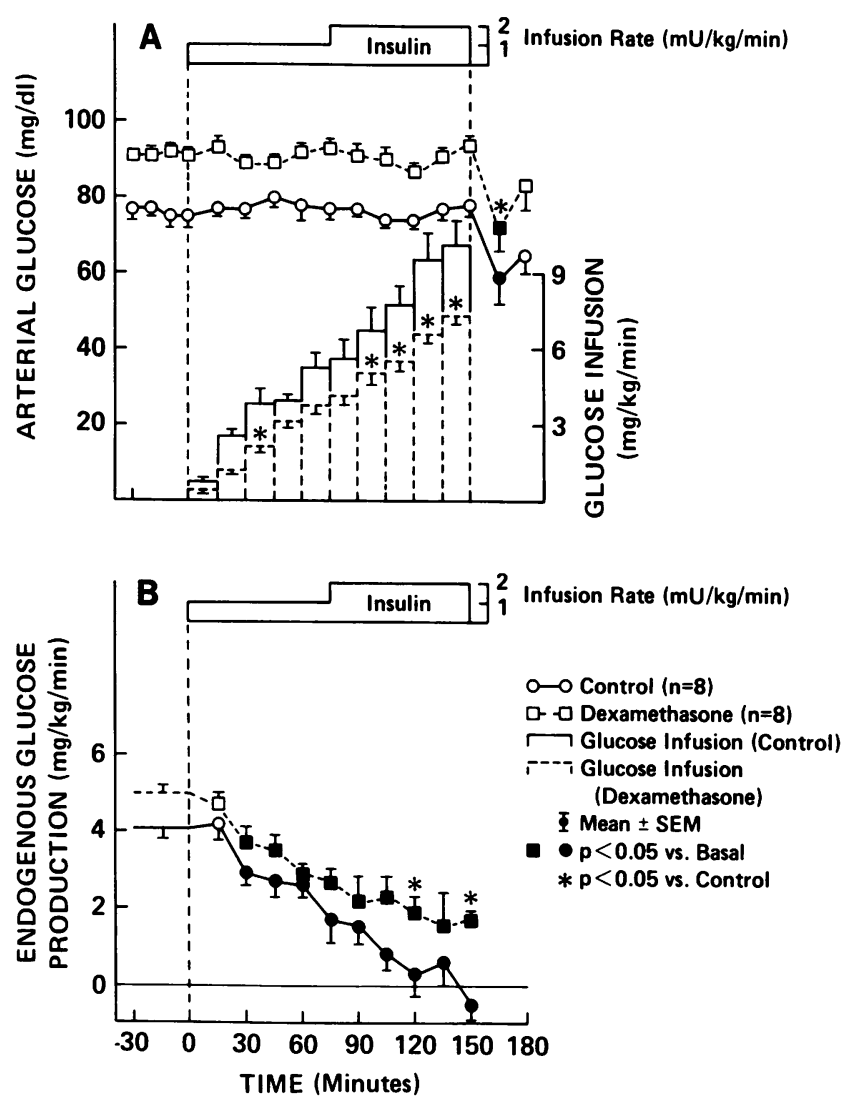

Figure 9. Insulin infusion into the portal system with euglycemic clamp. Rate of exogenous glucose infusion $(A)$ and endogenous glucose production $(B)$ in control and dexamethasone-treated $(2 \mathrm{mg} / \mathrm{d}$ for 7 d) dogs.

glucose disposal was diminished in the dogs treated with dexamethasone and hepatic glucose production was suppressed to a lesser degree than in the control animals. Such results confirm the previous observation that the insulin resistance of glucocorticoid excess involves both reduced use of glucose and decreased suppression by insulin of hepatic glucose output (2).

The peripheral insulin resistance has been attributed to postreceptor defects, based on reduced insulin responsiveness (2). Sensitivity has also been shown to be impaired, which suggests

Table I. Insulin Levels in Control and Dexamethasone-treated Dogs before and during Insulin Infusion

\begin{tabular}{|c|c|c|c|c|c|c|}
\hline \multirow[b]{3}{*}{ Vessel } & \multicolumn{6}{|c|}{ Plasma insulin $(\mu \mathrm{U} / \mathrm{ml})$} \\
\hline & \multicolumn{3}{|l|}{ Control } & \multicolumn{3}{|c|}{ Dexamethasone-treated } \\
\hline & Basal & Period I* & Period II & Basal & Period I* & Period II \\
\hline Portal vein & $21 \pm 5$ & $68 \pm 1$ & $127 \pm 2$ & $54 \pm 11$ & $81 \pm 3$ & $139 \pm 2$ \\
\hline Artery & $8 \pm 4$ & $27 \pm 1$ & $51 \pm 1$ & $21 \pm 5$ & $39 \pm 1$ & $65 \pm 2$ \\
\hline
\end{tabular}

Dexamethasone was given orally $(2 \mathrm{mg} / \mathrm{d}$ for $7 \mathrm{~d})$. Values for dexamethasone-treated dogs are $P<0.05$ vs. control values.

* Period I: the mean \pm SEM of five time points during the infusion of 1 $\mathrm{mU} / \mathrm{kg}$ per min of insulin from 0 to $75 \mathrm{~min}$.

\# Period II: the mean \pm SEM of five time points during the infusion of $2 \mathrm{mU} / \mathrm{kg}$ per min of insulin from 75 to $150 \mathrm{~min}$. 
possible additional abnormalities of receptor binding (3). Similarly, at the hepatic level, the insulin resistance could be due to reduced insulin binding, or to intracellular events reducing the effectiveness of the insulin-receptor complex. In the present studies, hepatic insulin resistance was apparent in that during the basal period net hepatic glucose production was not suppressed in the dexamethasone-treated dogs despite significantly higher portal vein insulin concentrations. Methyl prednisolone has been shown to potentiate the ability of both epinephrine (21) and glucagon (22) to increase hepatic glucose output. In our studies epinephrine was not measured but glucagon levels were similar in control and dexamethasone-treated animals.

The apparent increased absolute rate of glucose appearance after $7 \mathrm{~d}$ of dexamethasone treatment as measured isotopically may reflect further development of resistance as compared with $2 \mathrm{~d}$ of dexamethasone, or alternatively may simply reflect increased futile cycling. Methyl prednisolone has been reported to increase futile cycling in dogs $(23)$ and $\left[3-{ }^{3} \mathrm{H}\right]$ glucose is subject to this effect (24). Direct evaluation of the effect of glucocorticoid administration on hepatic insulin receptors has produced varied results. In cultured rat hepatocytes, dexamethasone stimulated insulin receptor synthesis, and depending on the conditions used, either inhibited or potentiated insulin action (25). However, administration of ACTH or dexamethasone to rats significantly decreased hepatic insulin receptor binding $(26,27)$, with some indication that the effect was tissue specific (26). Rizza et al. (2) found little change in insulin binding to erythrocytes or monocytes after cortisol infusion for $24 \mathrm{~h}$ but a significant shift to the right of the insulin dose response curve for suppression of hepatic glucose production.

Dexamethasone treatment was associated with a significant reduction in basal fractional hepatic extraction of insulin. This represents the first time that we have observed any reduction in basal fractional hepatic extraction of insulin. This does not appear to be a nonspecific effect because the fractional hepatic extraction of glucagon was very similar to that which we have previously reported (11). The reason for such lower fractional hepatic extraction of insulin is unknown. Whereas the possibility that fractional hepatic extraction of insulin may be related to changes in portal vein blood flow has been considered $(12,28)$, basal portal vein flow was not diminished in the dexamethasonetreated dogs. It is possible that the reduced fractional hepatic extraction of insulin reflects decreased insulin receptor number or affinity $(26,27)$. Although hepatic extraction of insulin is not the same as insulin degradation, with isolated hepatocytes, a close relationship existed between total cell-bound insulin and insulin degradation velocity $(29,30)$. However, Caro and Amatruda reported that after 1 wk of dexamethasone, isolated rat hepatocytes exhibited increased insulin degradation, although the relationship between degradation velocity and total bound insulin persisted (31).

After oral glucose administration, the fractional hepatic extraction of insulin significantly increased in the steroid-treated dogs. The increase was very similar to that observed in the control dogs but because it started from a lower basal value, the fractional hepatic extraction was still lower compared with the control dogs. The increased fractional hepatic extraction of insulin after oral glucose is similar to what we have reported previously (12). In contrast to those results, the increase in the dogs treated with dexamethasone was not associated with the usual increase in portal vein blood flow after oral glucose. This provides some additional evidence that increased portal vein flow is not pri- marily responsible for the augmented fractional hepatic extraction of insulin $(12,25)$. These results are different from those in which atropine administration inhibited both the increased portal vein blood flow and augmented fractional hepatic extraction of insulin after oral glucose (32). It is not known why oral glucose failed to produce an increase in portal vein flow in the dexamethasone-treated dogs, similar to thse seen in the control group, although this failure could be related to the smaller glucose absorption into the portal system.

Elevated insulin concentrations in conditions of glucocorticoid excess are usually attributed to increase insulin secretion in response to a rise in plasma glucose concentration (10). As judged by net nonhepatic splanchnic insulin balance, dexamethasone treatment did not significantly increase insulin secretion in these studies either in the basal state or after oral glucose. Because basal arterial glucose levels were higher in the dexamethasone treated groups, an increased secretion rate might have been expected. It is possible that the increased stimulus to secretion was opposed by a direct inhibitory effect of the corticosteroid at the B-cell level (4-9). The hyperinsulinemia observed would appear to be more attributable in these dogs to the reduced hepatic extraction of insulin than to an increased rate of secretion.

Administration of dexamethasone produced several other changes in carbohydrate metabolism. The fraction of the oral glucose ingested by the dogs that was released into the portal vein was significantly less after $2 \mathrm{~d}$ of dexamethasone. The explanation for this is not apparent although it could reflect diminished absorption of glucose from the gastrointestinal tract or greater use of glucose by that tissue. The latter seems less likely because the nonhepatic splanchnic glucose balance was very similar in the basal state in both the steroid-treated and control dogs. Although the absolute amount of glucose released into the portal system was less in the dogs treated with dexamethasone, the fraction of glucose taken up by the liver was greater. This is consistent with the observation that the net splanchnic output of glucose was greater in the control dogs. The finding that the incremental increase in fractional hepatic extraction of insulin and hepatic uptake of glucose after oral glucose were similar in the two groups does not necessarily indicate a causal relationship between the two. The possible relationship between fractional hepatic extraction of insulin and hepatic glucose uptake has been discussed previously (12). The increased hepatic uptake of glucose by the liver could reflect a direct action of steroids on the deposition of glucose into glycogen. Cortisol induced increased glycogen synthesis after glucose feeding in rats (33) and activation of glycogen synthetase in mice treated with prednisolone (34) has been reported. Although it is now believed that hepatic glycogen synthesis is largely via three carbon fragments rather than direct incorporation of glucose (35), the effects of steroids on glycogen metabolism could be independent of the pathway of synthesis. The effect could also serve partially or totally to overcome reduced insulin receptor function if such occurs with steroid treatment.

\section{Acknowledgments}

We are indebted to the staff of Cardiovascular Sciences for their superb help in the execution of these experiments, to Lucy Whitlock for her expertise in radioimmunoassay, and to Mary Harris and Mary Ann Farabee for their skill in the preparation of the manuscript.

This work was supported in part by U. S. Public Health Service grants AM-25253 and AM-27685. 


\section{References}

1. Perley, M., and D. M. Kipnis. 1966. Effect of glucocorticoids on plasma insulin. N. Engl. J. Med. 274:1237-1241.

2. Rizza, A. R., L. J. Mandarino, and J. E. Gerich. 1982. Cortisolinduced insulin resistance in man: impaired suppression of glucose production and stimulation of glucose utilization due to a postreceptor defect of insulin action. J. Clin. Endocrinol. \& Metab. 54:131-138.

3. Pagano, G., C. Cavallo-Perin, M. Cassader, A. Bruno, A. Ozzello, P. Masciola, A. M. Dallomo, and B. Imbibo. 1983. An in vivo and in vitro study of the mechanism of prednisone-induced resistance in healthy subjects. J. Clin. Invest. 72:1814-1820.

4. Barseghian, C., and R. Levine. 1980. Effect of corticosterone on insulin and glucagon secretion by the isolated perfused rat pancreas. Endocrinology. 106:547-552.

5. Billaudel, B., and B. Sutter. 1979. Direct effect of corticosterone upon insulin secretion studied by three different techniques. Horm. Metab. Res. 11:555-560.

6. Kalhan, S. C., and P. A. J. Adam. 1975. Inhibitory effect of prednisone on insulin secretion in man: model for duplication of blood glucose concentration. J. Clin. Endocrinol. \& Metab. 41:600-610.

7. Longano, C. A., and H. P. Fletcher. 1983. Insulin release after acute hydrocortisone treatment in mice. Metabolism. 32:603-608.

8. Marco, J., C. Calle, D. Roman, M. Diaz-Fierros, M. L. Villaneuva, and I. Valverde. 1973. Hyperglucagonism induced by glucocorticoid treatment in man. $N$. Engl. J. Med. 288:128-131.

9. Shamoon, H., V. Soman, and R. S. Sherwin. 1980. The influence of acute physiological increments of cortisol on fuel metabolism and insulin binding to monocytes in normal humans. J. Clin. Endocrinol. \& Metab. 50:495-501.

10. Beard, J. C., J. B. Halter, J. D. Best, M. A. Pfeifer, and D. Porte, Jr. 1984. Dexamethasone-induced insulin resistance enhances B cell responsiveness to glucose level in normal men. Am. J. Physiol. 247:E592E596.

11. Ishida, T., R. M. Lewis, C. J. Hartley, M. L. Entman, and J. B. Field. 1983. Comparison of hepatic extraction of insulin and glucagon in conscious and anesthetized dogs. Endocrinology. 112:1098-1109.

12. Ishida, T., Z. Chap, J. Chou, R. Lewis, C. Hartley, M. Entman, and J. B. Field. 1983. Differential effects of oral, peripheral intravenous, and intraportal glucose on hepatic glucose uptake and insulin and glucagon extraction in conscious dogs. J. Clin. Invest. 72:590-601.

13. Hartley, C. J., and J. S. Cole. 1974. An ultrasonic pulsed Doppler system for measuring blood flows in small vessels. J. Appl. Physiol. 37: 626-629.

14. Hartley, C. J., H. G. Hanley, R. M. Lewis, and J. S. Cole. 1978. Synchronized pulsed Doppler blood flow and ultrasonic dimension measurement in conscious dogs. Ultrasound Med. Biol. 4:99-110.

15. Herbert, V., K. S. Lau, C. W. Gottlieb, and S. J. Bleicher. 1965. Coated charcoal immunoassay of insulin. J. Clin. Endocrinol. \& Metab. 25:1375-1379.

16. Faloona, G. R., and R. H. Unger. 1974. Glucagon in Methods of Hormone Radioimmunoassay. B. M. Jaffe and H. R. Berman, editors. Academic Press, Inc., New York. 317-330.

17. Ishida, T., Z. Chap, J. Chou, R. M. Lewis, C. J. Hartley, M. L. Entman, and J. B. Field. 1984. Effects of portal and peripheral venous insulin infusion on glucose production and utilization in depancreatized, conscious dogs. Diabetes. 33:984-990.

18. Somogyi, M. 1945. Determination of blood sugars. J. Biol. Chem. 160:68-73.

19. Steele, R. 1959. Influence of loading and of injected insulin on hepatic glucose output. Ann. NY Acad. Sci. 82:420-430.

20. DeBodo, R., R. Steele, N. Altszuler, A. Dunn, and J. Bishop. 1963. On the hormonal regulation of carbohydrate metabolism: studies with ${ }^{14} \mathrm{C}$-glucose. Recent Prog. Horm. Res. 19:14130-14135.

21. Issekutz, B., and M. Allen. 1972. Effect of cathecholamines and methylprednisolone on carbohydrate metabolism of dogs. Metabolism. 21:48-59.

22. Issekutz, B., and I. Borkow. 1973. Effect of glucagon and glucose load on glucose kinetics, plasma FFA, and insulin in dogs treated with methylprednisolone. Metabolism. 22:39-49.

23. Issekutz, B. 1977. Studies on hepatic glucose cycles in normal and methylprednisolone-treated dogs. Metabolism. 26:157-170.

24. Bell, P. M., R. G. Firth, and R. A. Rizza. 1986. Effects of hyperglycemia on glucose production and utilization in humans. Diabetes. 35:642-648.

25. Salhanick, A. I., M. N. Krupp, and J. M. Amatruda. 1983. Dexamethasone stimulates insulin receptor synthesis in cultured rat hepatocytes. J. Biol. Chem. 250:8389-8398.

26. Olefsky, J. M., J. Johnson, F. Liu, P. Jen, and G. M. Reaven. 1975. The effects of acute and chronic dexamethasone administration on insulin binding to isolated rat hepatocytes and adipocytes. Metabolism. 24:517-527.

27. Kahn, C. R., I. D. Goldfine, D. M. Neville, Jr., and P. DeMeyts. 1978. Alterations in insulin binding induced by changes in vivo in the levels of glucocorticoids and growth hormone. Endocrinology. 103:1054 1066.

28. Chap, Z., T. Ishida, J. Chou, L. Michael, C. Hartley, M. Entman, and J. B. Field. 1986. Effects of alpha and beta adrenergic blockade on hepatic glucose balance before and after oral glucose. Role of insulin and glucagon. J. Clin. Invest. 77:1357-1369.

29. Terris, S., and D. F. Steiner. 1975. Binding and degradation of ${ }^{125}$ I insulin by rat hepatocytes. J. Biol. Chem. 250:8389-8398.

30. Juul, S. M., and R. H. Jones. 1982. Evidence for a direct effect of bacitracin on cell-mediated insulin degradation in isolated hepatocytes. Biochem. J. 206:295-299.

31. Caro, J. F., and J. M. Amatruda. 1982. Glucocorticoid-induced insulin resistance. The importance of postbinding events in the regulation of insulin binding, action, and degradation in freshly isolated and primary cultures of rat hepatocytes. J. Clin. Invest. 69:866-875.

32. Chap, Z., T. Ishida, J. Chou, R. Lewis, C. Hartley, M. Entman, and J. B. Field. 1985. Effects of atropine and gastric inhibitory polypeptide on hepatic glucose uptake and insulin extraction in conscious dogs. $J$. Clin. Invest. 76:1174-1181.

33. Friedmann, B., E. H. Goodman, Jr., and S. Weinhouse. 1967. Effects of glucose feeding, cortisol, and insulin on liver glycogen synthesis in the rat. Endocrinology. 81:486-496.

34. DeWulf, H., and H. G. Hers. 1968. The role of glucose, glucagon and glucocorticoids in the regulation of liver glycogen synthesis. Eur. $J$. Biochem. 6:558-564.

35. Katz, J., and J. D. McGarry. 1984. The glucose paradox. Is glucose a substrate for liver metabolism? J. Clin. Invest. 74:1901-1909. 